\title{
Synthesis of fluorescent core-shell nanomaterials and strategies to generate white light
}

Amandeep Singh, Ramanjot Kaur, O. P. Pandey, Xueyong Wei, and Manoj Sharma

Citation: Journal of Applied Physics 118, 044305 (2015);

View online: https://doi.org/10.1063/1.4927482

View Table of Contents: http://aip.scitation.org/toc/jap/118/4

Published by the American Institute of Physics

\section{Articles you may be interested in}

Blue and green electroluminescence from CdSe nanocrystal quantum-dot-quantum-wells

Applied Physics Letters 105, 203101 (2014); 10.1063/1.4902109

Fluorescence lifetime of Mn-doped ZnSe quantum dots with size dependence

Applied Physics Letters 92, 241111 (2008); 10.1063/1.2945274

Exciton radiative recombination in spherical $\mathrm{Cd} S$ / $\mathrm{CdSe} / \mathrm{Cd} S$ quantum-well nanostructures

Applied Physics Letters 87, 043107 (2005); 10.1063/1.2001731

Improved luminescence from CdSe quantum dots with a strain-compensated shell

Applied Physics Letters 102, 023106 (2013); 10.1063/1.4775678

Controlling blinking in multilayered quantum dots

Applied Physics Letters 96, 151107 (2010); 10.1063/1.3396985

The electronic properties of a two-electron multi-shell quantum dot-quantum well heterostructure Journal of Applied Physics 114, 043706 (2013); 10.1063/1.4816099

\section{Scilight}

Sharp, quick summaries illuminating the latest physics research

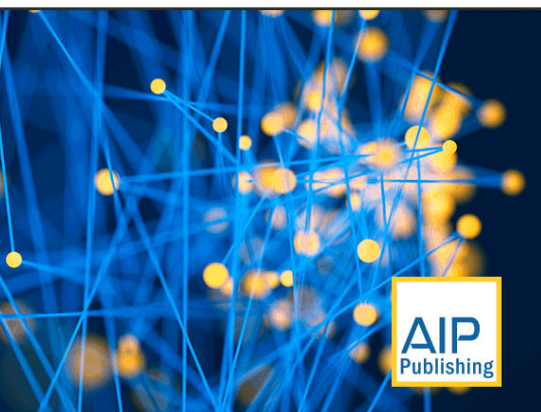




\title{
Synthesis of fluorescent core-shell nanomaterials and strategies to generate white light
}

\author{
Amandeep Singh, ${ }^{1}$ Ramanjot Kaur, ${ }^{1}$ O. P. Pandey, ${ }^{2}$ Xueyong Wei, ${ }^{3}$ and Manoj Sharma ${ }^{1,4, a)}$ \\ ${ }^{1}$ Department of Nanotechnology, Sri Guru Granth Sahib World University, Fatehgarh Sahib, India \\ ${ }^{2}$ School of Physics and Materials Science, Thapar University, Patiala 147004, India \\ ${ }^{3}$ State Key Laboratory for Manufacturing System Engineering, Xi' an Jiaotong University, 710049 Xi' an, \\ China \\ ${ }^{4}$ UNAM-Institute of Materials Science and Nanotechnology, Bilkent University, Ankara 06800, Turkey
}

(Received 30 January 2015; accepted 16 July 2015; published online 28 July 2015)

\begin{abstract}
In this work, cadmium free core-shell $\mathrm{ZnS}: \mathrm{X} / \mathrm{ZnS}(\mathrm{X}=\mathrm{Mn}, \mathrm{Cu})$ nanoparticles have been synthesized and used for white light generation. First, the doping concentration of Manganese (Mn) was varied from $1 \%$ to $4 \%$ to optimize the dopant related emission and its optimal value was found to be $1 \%$. Then, $\mathrm{ZnS}$ shell was grown over $\mathrm{ZnS}: \mathrm{Mn}(1 \%)$ core to passivate the surface defects. Similarly, the optimal concentration of Copper $(\mathrm{Cu})$ was found to be $0.8 \%$ in the range varied from $0.6 \%$ to $1.2 \%$. In order to obtain an emission in the whole visible spectrum, dual doping of Mn and $\mathrm{Cu}$ was done in the core and the shell, respectively. A solid-solid mixing in different ratios of separately doped quantum dots (QDs) emitting in the blue green and the orange region was performed. Results show that the optimum mixture of QDs excited at $300 \mathrm{~nm}$ gives Commission Internationale del'Éclairage color coordinates of $(0.35,0.36)$, high color rendering index of 88 , and correlated color temperature of $4704 \mathrm{~K}$ with minimum self-absorption. (C) 2015 AIP Publishing LLC.
\end{abstract}

[http://dx.doi.org/10.1063/1.4927482]

\section{INTRODUCTION}

In the last two decades, transition metal doped semiconductor nanocrystals have been widely investigated because of their tunable emission spanning over the whole visible region. $^{1-12}$ Among them, $\mathrm{Mn}$ and $\mathrm{Cu}$-doped semiconductor nanocrystals were of great importance as $\mathrm{Mn}$ provides a short-range emission and $\mathrm{Cu}$ results in a host bandgapdependent wide range tunable emission. ${ }^{11,12}$ Therefore, their tunable PL emissions can be used to generate white light. The quality of a white light source is usually evaluated by three performance parameters: CIE, CRI, and CCT ${ }^{10}$ In CIE (Commission Internationale del'Éclairage) color diagram, a perfect white light is produced at a point $(\mathrm{x}, \mathrm{y})=(0.33$, 0.33). ${ }^{10}$ Color rendering index $(\mathrm{CRI})$ is the measure of color rendition of the white light source. The best color rendition is expressed with a CRI of 100, whereas the CRI of the poorest color rendition is expressed as -100 . Furthermore, the quality of a light source is also evaluated in terms of the correlated color temperature (CCT), which illustrates the temperature of a closest Planckian black-body radiator to the operating point on the chromaticity diagram. ${ }^{10}$

There are various methods to achieve white-light emission. The first one is the multichip white LEDs which consist of red, blue, and green emitting chips and thus shows a good CRI. However, these types of LEDs are costly and have complex electronic system to account for different degradation rate of different types of chips. The second type is the $\mathrm{ZnSe}$ based white LEDs which have two emission bands: blue from the active layer of $\mathrm{ZnSe}$ and yellow from the $\mathrm{ZnSe}$

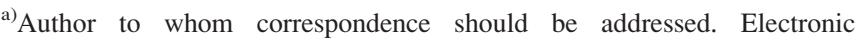
addresses: manojnarad@gmail.com and manojsharma@bilkent.edu.tr
}

substrate. ${ }^{10}$ However, these types of LEDs have lower emission efficiency and shorter lifetime comparatively. The third type is the single chip white LEDs that comprises blue InGaN chip and yellow emitting yttrium aluminum garnet (YAG) phosphor. ${ }^{10}$ The YAG doped with cerium (YAG: Ce) phosphor is most widely used in these types of LEDs. However, this leads to a low CRI value as the YAG: Ce phosphor lacks emission in the red region. The application of QDs as down converter in white LEDs has been employed to improve the CRI values. ${ }^{10,11}$ Therefore, white light emission can be obtained by mixing different color emitting QDs together, but it may lead to a poor photometric performance and undesirable changes in CIE coordinates. ${ }^{12,13}$ This is mainly due to self-absorption of QDs and an improper mixing of all the emissions will lead to a poor white light generation. To address this problem, a single system emitting different colors was achieved by synthesizing doped QDs in solution having different dopants. However, the host matrix tends to expel the dopant ions from the internal crystal lattice to the surface in sort of self- purification process. ${ }^{14}$ Hence doping is difficult even in most favorable cases of dopants having same charge and ionic radius as that of host. Nag and Sharma ${ }^{15}$ reported white light generation from Mn doped $\mathrm{CdS}$ nanocrystals and addressed the problem of selfabsorption in nanocrystals caused by the large stoke shift in absorption and emission spectra. However, cadmium is a highly toxic material and hence hazardous to the environment. Also covering whole visible spectrum for perfect white light generation from single dopant ions is not possible. Another approach adopted to address this problem was codoping. Mostly, it has been observed that during co-doping the emission from one of the dopants is suppressed by the other due to the interaction between the dopants. There are 
several reports describing the synthesis of semiconductor nanocrystals (NCs) with white light emission such as $\mathrm{CdSe}$ NCs, alloyed $\mathrm{Zn}_{\mathrm{x}} \mathrm{Cd}_{1-\mathrm{x}} \mathrm{Se}$ QDs, ZnS:Pb, and ZnS incorporated into porous silicon, $\mathrm{Mn}, \mathrm{Cu}$ co-doped $\mathrm{ZnSe}$, and ZnS:Mn QDs. ${ }^{16-21}$

It is expected that a high quality white light emission from a mixture of differently doped QDs can be achieved. The problems associated with a simple mixing are reabsorption of the emitted photon by other QDs, excitation of mixture of QDs at different wavelengths, and out of phase emission of different QDs. These will lead to a poor CRI and an unwanted change in CIE as redundant color hues will be present in output. ${ }^{22}$ Herein, we report the synthesis of highly luminescent core/shell ZnS:X/ZnS $(\mathrm{X}=\mathrm{Mn}, \mathrm{Cu}) \mathrm{NPs}$ and nearly perfect white light emission from a mixture of differently doped QDs. First, $\mathrm{ZnS}: \mathrm{Mn}$ and $\mathrm{ZnS}: \mathrm{Cu}$ cores were synthesized and the optimal doping concentrations were experimentally worked out. Then $\mathrm{ZnS}$ shell was grown over the core to passivate the surface defects. The advantage of inorganic shell is experimentally verified by increase in overall emission and quantum efficiency. The core-shell QDs with dual doping (doping in core and shell, respectively) strategies were tried to cover the whole visible spectrum. However, the co-doping was not achievable due to mild conditions of synthesis. Solid-solid mixing of two separately doped core shell QDs was instead studied in order to span the complete visible spectrum. Finally, superior white light performance having CIE color coordinates of $(0.35,0.36)$, high CRI of 88 and CCT of $4704 \mathrm{~K}$ with minimum selfabsorption was achieved by tuning the relative concentration of the highly luminescent QDs and using a single wavelength excitation source.

\section{EXPERIMENTAL DETAILS}

\section{A. Materials and chemicals}

Analytically pure zinc acetate $\left(\mathrm{Zn}\left(\mathrm{CH}_{3} \mathrm{COO}\right)_{2}\right)$, manganese acetate tetra-hydrate $\left(\mathrm{Mn}\left(\mathrm{CH}_{3} \mathrm{COO}\right)_{2} \cdot 4 \mathrm{H}_{2} \mathrm{O}\right)$, sodium sulphide nona-hydrate $\left(\mathrm{Na}_{2} \mathrm{~S} \cdot 9 \mathrm{H}_{2} \mathrm{O}\right)$, and copper acetate $\left(\mathrm{Cu}\left(\mathrm{CH}_{3} \mathrm{COO}\right)_{2}\right)$ were used as-received from Sigma Aldrich. Other chemical reagents were used without further purification.

\section{B. Experimental procedures}

The bottom up wet chemical synthesis route was used to synthesize orange and green emitting core shell NPs. ${ }^{23}$ The Zinc Sulphide $(\mathrm{ZnS})$ core was doped with Manganese (Mn) and Copper $(\mathrm{Cu})$ separately. The shell of $\mathrm{ZnS}$ was formed over the doped core. Further efforts were done to synthesize dual doped NPs with Mn doped in core and $\mathrm{Cu}$ doped in shell under mild synthesis environment. The experimental details are given below.

\section{Synthesis of $\mathrm{ZnS}: \mathrm{X}$ core $(\mathrm{X}=\mathrm{Mn}, \mathrm{Cu})$}

The aqueous stock solution was prepared as follows: $0.5 \mathrm{M}$ solution of zinc precursor was prepared by adding $9.17 \mathrm{~g}$ of zinc acetate in $100 \mathrm{ml}$ double distilled water. Then, the amount of zinc acetate was varied and manganese acetate (or copper acetate) was added to the solution, to vary the doping concentration from 1.0 to $4.0 \%$ at. for $\mathrm{Mn}$ (or 0.6 to $1.2 \%$ at. for $\mathrm{Cu}$ ). Thus, zinc precursor solution with different amount of dopants was vigorously stirred at a constant temperature of $80^{\circ} \mathrm{C} .40 \mathrm{ml}$ of $0.5 \mathrm{M}$ thioglycerol (TG) solution was prepared by mixing $1730 \mu \mathrm{l} \mathrm{TG}$ in $40 \mathrm{ml}$ of the double distilled water. An appropriate amount of $0.5 \mathrm{M}$ Sodium Sulphide $\left(\mathrm{Na}_{2} \mathrm{~S}\right)$ was prepared as a reducing agent.

Sample preparation: $20 \mathrm{ml}$ of buffer solution of zinc acetate doped with $\mathrm{Mn}$ (or $\mathrm{Cu}$ ) was taken in a flask and $40 \mathrm{ml}$ solution of capping agent (TG) was added to it. The above solution was stirred for $5 \mathrm{~min}$ at $80^{\circ} \mathrm{C}$. $0.5 \mathrm{M}$ Sodium Sulphide $\left(\mathrm{Na}_{2} \mathrm{~S}\right)$ was added to above mixture drop-wise and temperature was reduced to $70^{\circ} \mathrm{C}$, while stirring was continued. Finally, the above mixture was stirred for $12 \mathrm{~h}$ with a slow increase in temperature to $80^{\circ} \mathrm{C}$. The solid powders of $\mathrm{ZnS}: \mathrm{Mn} / \mathrm{Cu}$ core NPs were obtained after adding excess ethanol to the solution followed by drying in vacuum.

\section{Synthesis of ZnS:X/ZnS core-shell NPs ( $\mathrm{X}=\mathrm{Mn}, \mathrm{Cu}$ )}

Zinc acetate and TG stock solution of $0.5 \mathrm{M}$ concentration was prepared by adding an appropriate amount of zinc acetate and TG into aqueous solution [labeled as solution A]. The powder of NPs formed in Section IIC was dissolved in DI water so that final concentration of solution is $0.05 \mathrm{M}$. $20 \mathrm{ml}$ stock solution was added into the NPs solution drop wise and the mixture was stirred for $6 \mathrm{~h}$ at the temperature of $80^{\circ} \mathrm{C}$. Finally, $\mathrm{ZnS}: \mathrm{X} / \mathrm{ZnS}$ core shell NPs were obtained after adding excess ethanol and drying in vacuum.

\section{E. Synthesis of dual doped NPs (ZnS:Mn/ZnS:Cu)}

The synthesis of core doped with Mn was done in a similar way as did in step one (Section IIC). The powder of Mn doped NPs formed in Section IIC was dissolved in DI water, so that final concentration of solution is $0.05 \mathrm{M}$. This sample is used as core for dual doped synthesis. For $\mathrm{Cu}$ doped shell growth, the aqueous stock solution $(0.1 \mathrm{M})$ of zinc acetate and copper acetate were prepared, under vigorously stirring and maintaining a constant temperature of $80{ }^{\circ} \mathrm{C}$. The doping concentration of $\mathrm{Cu}$ was $0.8 \%$ (at.). Then, $0.1 \mathrm{M}$ TG solution was added and labeled as solution B. Both the solutions (ZnS:Mn core and solution B) were mixed and stirred continuously for $6 \mathrm{~h}$ at $80^{\circ} \mathrm{C}$, so that $(\mathrm{ZnS}: \mathrm{Cu})$ shell grows over the core (ZnS:Mn) NPs. The dual doped material $\mathrm{ZnS}: \mathrm{Mn} / \mathrm{ZnS}: \mathrm{Cu}$ was obtained after adding excess ethanol and drying in vacuum.

\section{F. Formation of mixture of QDs}

The powder samples of both QDs (ZnS:Mn/ZnS and $\mathrm{ZnS}: \mathrm{Cu} / \mathrm{ZnS}$ ) were used to make equal concentration $(0.01 \mathrm{M})$ of aqueous QDs colloidal solution. Seventeen samples were prepared with various ratios of both the solutions (Table S1, Ref. 24) to study the effect of different QDs on the overall luminescence property.

Thus, by following the above procedure these samples were prepared: $\mathrm{ZnS}: \mathrm{Mn}$ core NPs, ZnS:Mn/ZnS core-shell 
NPs, ZnS: $\mathrm{Cu}$ core NPs, ZnS:Cu/ZnS core-shell NPs, $\mathrm{ZnS}: \mathrm{Mn} / \mathrm{ZnS}: \mathrm{Cu}$ (dual doped) coreshell NPs, and ZnS:Mn/ $\mathrm{ZnS}+\mathrm{ZnS}: \mathrm{Cu} / \mathrm{ZnS}$ mixed QDs. The schematic of synthesized NPs showing white-light is shown in Figure 1.

\section{G. Instrumentation and measurements}

The NPs were characterized by X-ray diffraction (XRD) using Panalytical X'pert Pro MPD with $\mathrm{Cu}-\mathrm{K} \alpha$ radiation. HRTEM images of synthesized samples were recorded using analytical transmission electron microscope (Model JEM2100F). For HRTEM study, a drop of the QD solution dispersed in methanol was dropped on a carbon-coated $\mathrm{Cu}$ grid. Methanol was evaporated to leave QDs on the grid. Optical absorption spectra of the ZnS NPs were recorded with a double beam UV-Visible spectrophotometer (Model: Shimadzu/ UV 2600) in the range of $200-800 \mathrm{~nm}$. Photoluminescence studies and calculation of CIE color coordinates of all the prepared samples were done with an Edinburgh Instruments FS920 spectrometer equipped with a 450W Xenon Arc Lamp and a cooled single photon counting photomultiplier (Hamamatsu R2658P). For PL (excitation and emission) studies, ZnS NPs in equal concentration were used. Absolute quantum yields (QYs) were measured using an integrating sphere and a Xenon lamp as excitation source.

\section{RESULTS AND DISCUSSION}

\section{A. Structural studies}

$\mathrm{X}$-ray diffraction pattern of $\mathrm{ZnS}$ doped core and coreshell NPs shows three broad peaks corresponding to the (111), (220), and (311) planes of FCC ZnS structure (Figure S1, Ref. 24). The peaks observed in the XRD pattern match well with those of the $\beta$ - ZnS (cubic) reported in the ICDD Powder Diffraction files (File. No. 77-2100). Crystallite size of ZnS NPs was calculated by Scherer's equation which is in the range of $4.0-5.0 \mathrm{~nm}$ for core and core-shell QDs. Broadening of the XRD peaks for capped samples indicates the formation of $\mathrm{ZnS}$ nanocrystals. The nanocrystals have

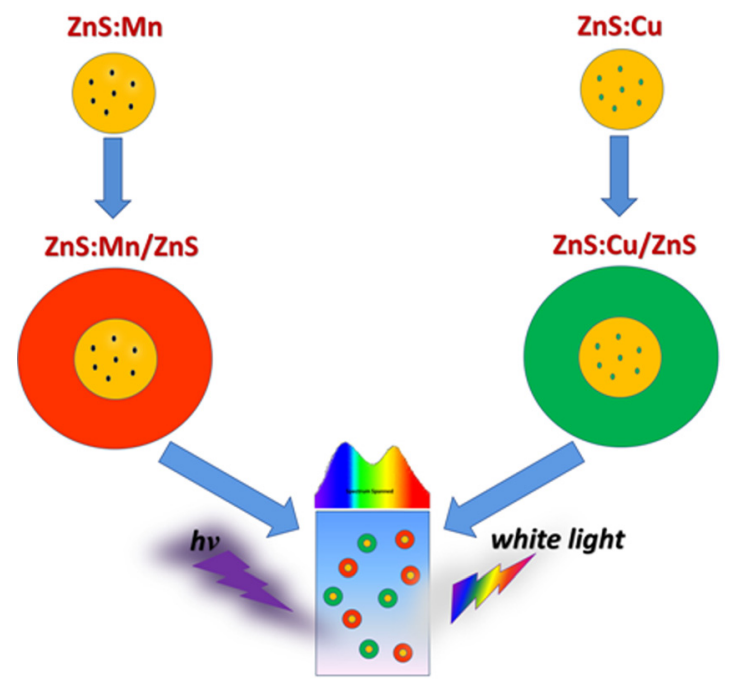

FIG. 1. Schematic of formation of doped core-shell QDs and white light generation. lesser lattice planes compared to bulk which contributes to the broadening of peaks in the diffraction pattern. There is a little shift in diffraction peaks to larger angles as the shell is formed. No characteristic peaks of impurity phases are observed in the XRD pattern, indicating the high purity of the final products.

Figure 2(a) shows the high-resolution TEM (HRTEM) image of $\mathrm{ZnS}: \mathrm{Mn} / \mathrm{ZnS}$ core shell NPs (scale bar: $5 \mathrm{~nm}$ ). The inset (b) shows magnified image of single NP. Since the core and the shell of the QDs had similar electron densities and lattice parameters, but doping in core creates slight image contrast that distinguishes the shell and the core. The high crystallinity of the prepared NPs is justified since the distance $(0.317 \mathrm{~nm})$ between the adjacent lattice fringes is the interplanar distance of $\mathrm{ZnS}\langle 111\rangle$ plane, which is in a good agreement with the $\langle 111\rangle \mathrm{d}$-spacing value of $0.312 \mathrm{~nm}$ reported in literature. ${ }^{25}$ The high crystallinity of NPs depends upon the rate of reaction. The reducing agent mentioned in Section IIC was added drop-wise and at same time temperature was reduced to slow down the rate of reaction which promotes narrow size distribution. Figure 2(c) shows the HRTEM image of $\mathrm{ZnS}: \mathrm{Cu} / \mathrm{ZnS}$ at scale bar $10 \mathrm{~nm}$. Inset figure shows magnified image of single NP, which clearly shows the lattice planes. Figure 2(d) shows the HRTEM image of $\mathrm{ZnS}: \mathrm{Cu} / \mathrm{ZnS}$ at scale bar $5 \mathrm{~nm}$. From TEM measurements, it is observed that all synthesized QDs are having average size of 5-6 nm.

\section{B. Absorption studies}

Optical studies were performed by measuring the absorption of the samples in the wavelength range of $200-800 \mathrm{~nm}$. Figure 3(a) shows absorbance versus wavelength $(\lambda)$ graph for $\mathrm{ZnS}: \mathrm{Mn} / \mathrm{ZnS}$ core shell QDs. The absorption spectrum of
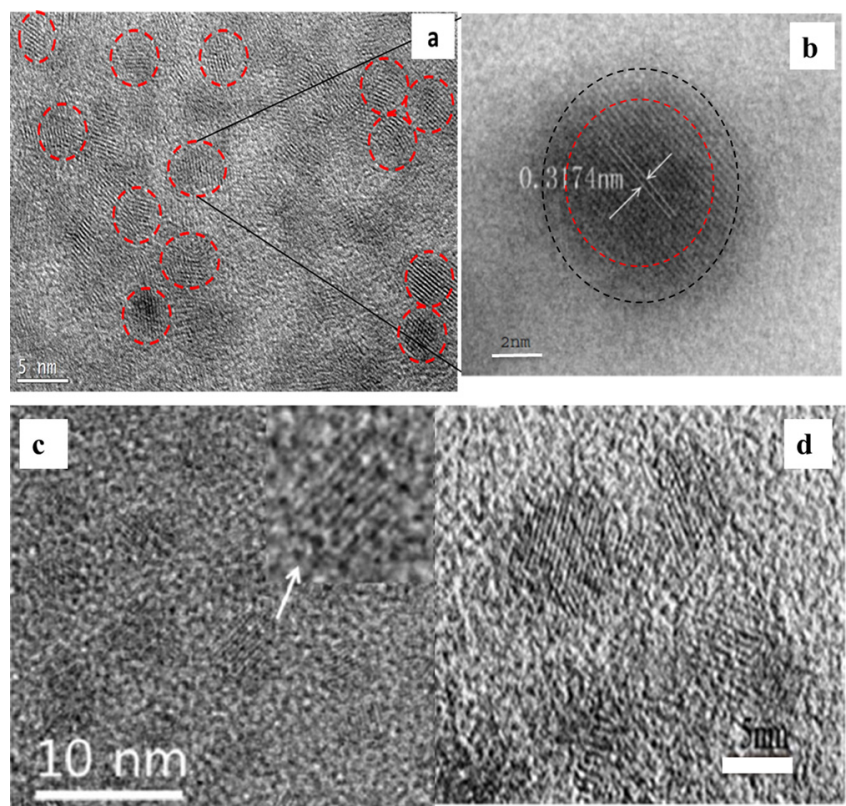

FIG. 2. (a) The High-Resolution TEM (HRTEM) image of ZnS:Mn/ZnS core shell NPs (scale bar: $5 \mathrm{~nm}$ ). The inset (b) shows magnified image of single NP, (c) the HRTEM image of $\mathrm{ZnS}: \mathrm{Cu} / \mathrm{ZnS}$ at scale bar $10 \mathrm{~nm}$. Inset figure shows magnified image of single NP, (d) the HRTEM image of $\mathrm{ZnS}: \mathrm{Cu}$ / $\mathrm{ZnS}$ at scale bar $5 \mathrm{~nm}$. 
QDs shows absorption edge at $300 \mathrm{~nm}$. Thus, the absorption edge has fairly blue shifted as compared to that of the bulk $(334 \mathrm{~nm})$. The absorption coefficients $(\alpha)$ were obtained in the region of strong absorption by calculating the transmittance data using Manifacier model. ${ }^{26}$ To determine the band gap of synthesized QDs, the fundamental absorption which corresponds to the transition from valence band to the conduction band was used. The relation between absorption coefficient $(\alpha)$ and incident photon energy $(\mathrm{h} \nu)$ can be written $\mathrm{as}^{26}$

$$
\alpha=\mathrm{A}\left(\mathrm{h} \nu-\mathrm{E}_{\mathrm{g}}\right)^{\mathrm{n}} / \mathrm{h} \nu
$$

where A is constant, $\mathrm{E}_{\mathrm{g}}$ is the band gap of the material, and the exponent $\mathrm{n}$ depends on the type of transition. The value of $\mathrm{n}$ is $1 / 2,2,3 / 2$, and 3 corresponding to the allowed direct, allowed indirect, forbidden direct, and forbidden indirect transitions, respectively. The exact value of band gap can be determined by extrapolating the straight line portion of the $(\alpha \mathrm{h} \nu)^{1 / \mathrm{n}}$ versus $\mathrm{h} \nu$ axis (Fig. S2, Ref. 24). The band gap value decreases with increasing doping concentration. This is due to the change of particle size which increases with increasing doping concentration of Mn ion. Similar results were reported by Kole et al. ${ }^{12}$ Further for all synthesized samples band gap is larger than the band gap of corresponding bulk $\mathrm{ZnS}(3.6 \mathrm{eV})$, which is due to the strong quantum confinement effects. The formation of shell over the core leads to a small red shift $(5-10 \mathrm{~nm})$ in UV-Visible absorption spectra wavelength compared to the uncoated core. A shift of $8 \mathrm{~nm}$ was observed in case of $\mathrm{ZnS}: \mathrm{Cu}$ (core) vs. $\mathrm{ZnS}: \mathrm{Cu} /$ $\mathrm{ZnS}$ (core-shell) QDs, as shown in Figure 3(b). In the case of Mn doped core vs. Core-shell QDs the shift was $10 \mathrm{~nm}$ (Figure 3(c)).

\section{Luminescence studies}

Figure 4(a) shows emission mapping of $\mathrm{ZnS}: \mathrm{Mn} / \mathrm{ZnS}$ core shell NPs. The excitation wavelength varies from $280 \mathrm{~nm}$ to $340 \mathrm{~nm}$, with step size of $10 \mathrm{~nm}$. The excitation wavelength of sample prepared is $300 \mathrm{~nm}$ since at this particular excitation, the emission from sample is maximum. This is also visible from the excitation scan of sample corresponding to dopant emission at $590 \mathrm{~nm}$ (Figure 4(b)). Earlier we have shown tunable emission in the inorganic-organic hybrid NPs by FRET (Foster Resonance Energy Transfer) mechanism. ${ }^{23,27}$ CIE chromaticity coordinates shifts from $(0.27$, $0.20)$ to $(0.34,0.27)$ for chitosan capped and Mn doped $\mathrm{ZnS}$ QDs by suitably tuning excitation energy in the higher and lower ultra-violet (UV) range. These materials can be used for bio-sensing applications, but the photometric properties of these NPs were not superior. For the opto-electronic and lighting application, the emission must be tuned to achieve superior photometric properties like CRI (better than 85), CIE close to white light $(0.33,0.33)$. Quan et $a l .{ }^{21}$ reported a multi-color tuning of $\mathrm{Mn}$ doped $\mathrm{ZnS}$ colloidal nanocrystals under single excitation wavelength. White emission was realized for $\mathrm{Mn}^{2+}$ doped $\mathrm{ZnS}$ nanocrystals, with a good CIE co-ordinate $(0.31,0.30)$. However, they did not report the CRI values, which indicate the color quality.

To improve the color quality, the output in visible region should be tuned, especially in deep green to yellow region of spectrum, thereby addressing the green window problem. ${ }^{10}$ Figure 4(c) shows the dependence of luminescence intensity on the doping concentration of Mn. First, the doping concentration of $\mathrm{Mn}$ in core of core-shell system was varied from 1 to $4 \%$ (at.) to optimize the emission. It was observed that the characteristic emission due to Mn doping was found to be
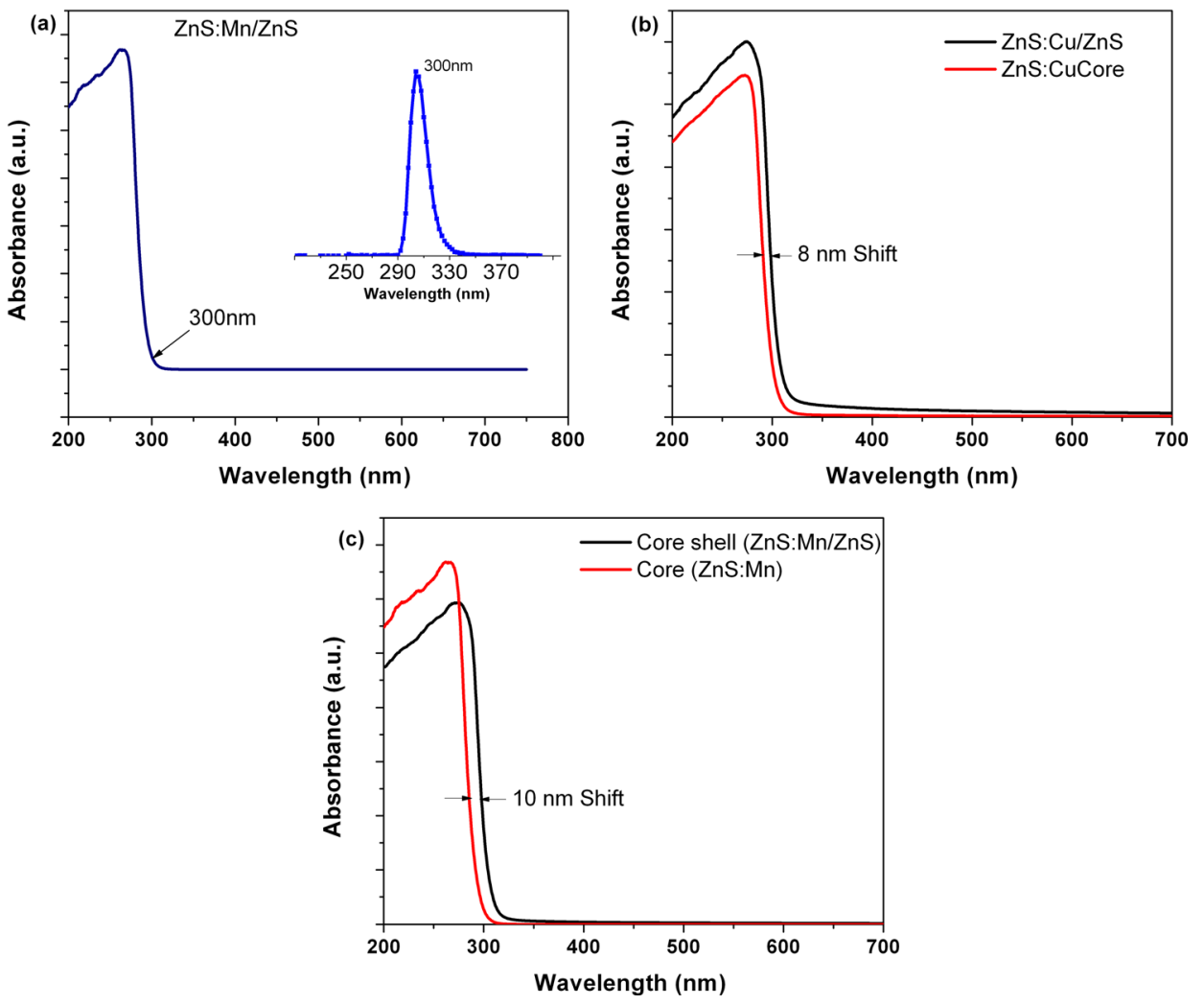

FIG. 3. (a) Absorption spectrum of $\mathrm{ZnS}: \mathrm{Mn} / \mathrm{ZnS}$ core shell QDs, with absorption edge at $300 \mathrm{~nm}$. The Inset is the excitation scan of sample which shows peak at same wavelength. (b) Shift in UV spectrum due to formation of shell. (c) Absorption spectrum of $\mathrm{ZnS}: \mathrm{Cu} / \mathrm{ZnS}$ core-shell QDs. 

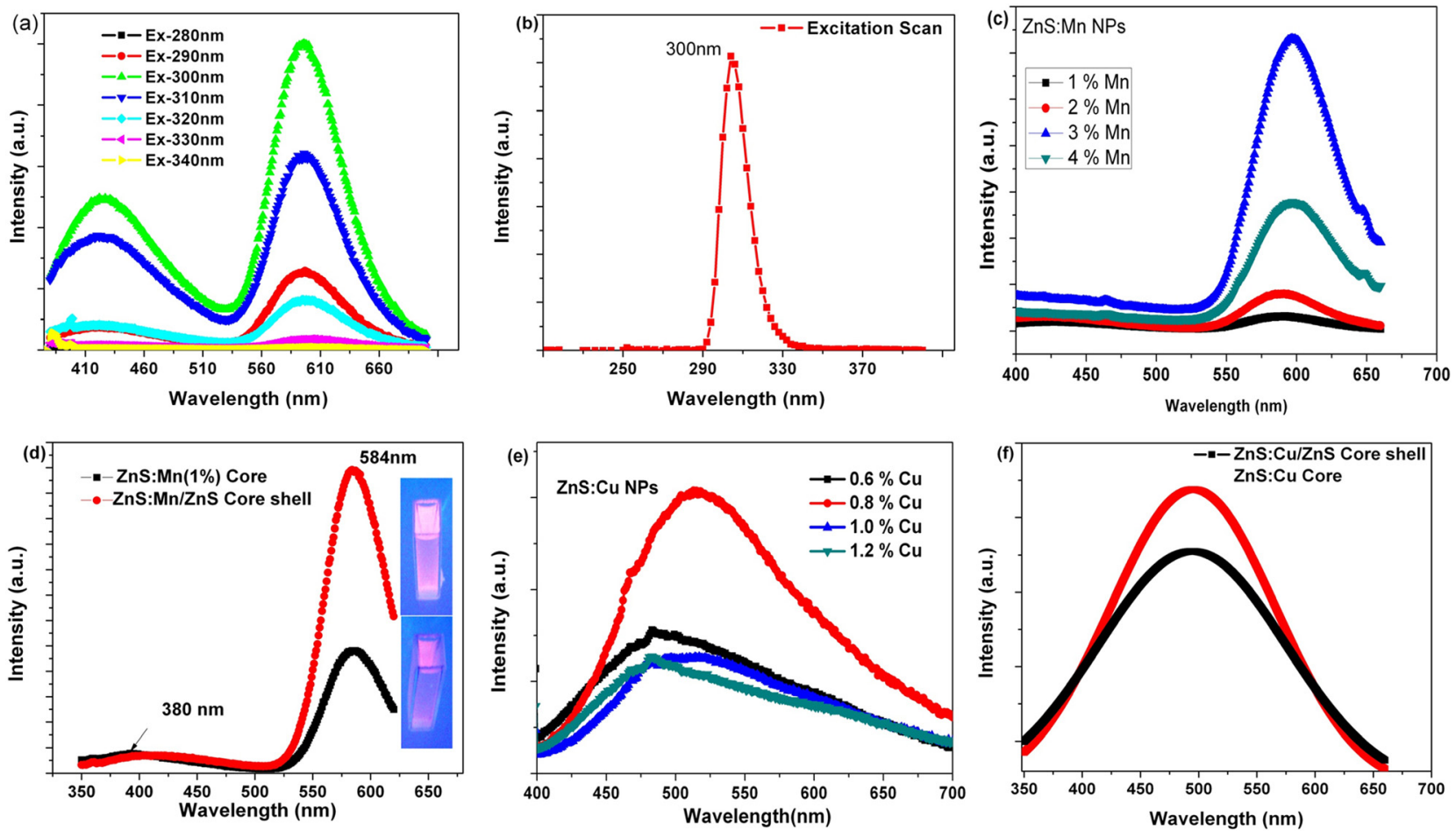

FIG. 4. (a) Photo luminescence emission spectra of ZnS:Mn/ZnS core shell NPs at different excitation wavelength, (b) excitation spectra of ZnS:Mn/ZnS core shell NPs corresponding to dopant emission at $590 \mathrm{~nm}$, (c) variation of luminescence of ZnS: Mn with doping concentration, (d) PL of core and core-shell ZnS NPs with 1\% (at. wt.) doping of Mn, (e) variation of luminescence of ZnS: Cu NPs with different Cu concentration, (f) PL spectrum of core and core-shell NPs with $0.8 \%$ (at. wt.) doping of $\mathrm{Cu}$.

dependent on doping concentration of $\mathrm{Mn}$ in $\mathrm{ZnS}$. The optimum concentration was found to be near $1 \%$ (at.). The similar concentration was quoted by Kole et al. ${ }^{12}$ It has been observed that as the doping concentration increases above $1 \%$, the luminescence intensity decreases. Figure 4(d) shows emission spectra of core ( $\mathrm{ZnS}: \mathrm{Mn})$ vs. core-shell ( $\mathrm{ZnS}: \mathrm{Mn} /$ $\mathrm{ZnS}$ ) QDs at $300 \mathrm{~nm}$ excitation wavelength. The inset shows bright colloidal solution of QDs under UV illumination. The core has two characteristic emissions, one related to defect/ vacancy related emission of host $\mathrm{ZnS}$ material close to $400 \mathrm{~nm}$ and other is dopant related emission $\left({ }^{4} \mathrm{~T}_{1} \rightarrow{ }^{6} \mathrm{~A}_{1}\right)$ of $\mathrm{Mn}^{2+}$ close to $590 \mathrm{~nm} .{ }^{23,28,29}$ It is because the NPs have high surface to volume ratio that surface defects can quench the emission by providing the alternative path of nonradiative relaxation. The formation of the shell (inorganic capping) over the core not only passivates these defects but at the same time can also satisfy cationic and anionic dangling bonds, thereby blocking the alternative path for nonradiative transition. The ratio of emission intensity from dopant (DOP) vs defect (DF) in case of core QDs is IDOP/ $\mathrm{DF}(\mathrm{C})=6.07$, while in case of core-shell QDs, IDOP/DF (CS) is 15.07 (Figure 4(d)). Thus, the relative increase of $59.7 \%$ has been observed in core/shell NPs. These results imply that the passivation of surface defects by shell significantly enhances the dopant related emission in comparison with defects related emission.

Similarly, the doping concentration of $\mathrm{Cu}$ in $\mathrm{ZnS}: \mathrm{Cu}$ NPs was varied from 0.6 to $1.2 \%$ (at.) to find out the optimized emission from the samples (Figure 4(e)). It has been reported earlier that the PL emission peak around $434 \mathrm{~nm}$ for undoped $\mathrm{ZnS}$ is attributed to the sulfur vacancies and $\mathrm{ZnS}$ QDs will have a large number of sulfur vacancies (VS) during precipitation at low concentrations of sulfide ions. ${ }^{27,30,31}$ Bearing a charge of $2+$, the VS sites can effectively trap excited electrons from the conduction band and act as a doubly ionized donor by forming a shallow energy level below the conduction band (CB) edge. Subsequent electron-hole (e-h) recombination at the valence band lead to blue emissions, referred to as "self-activated" emission in nanosized $\mathrm{ZnS}^{30}$ As shown in Figure 4(e), broad emission peak from 400 to $600 \mathrm{~nm}$ is observed which shows contribution from sulfur vacancies and dopant states. In addition, there is a small variation in peak position (red shift) with increased $\mathrm{Cu}$ doping. The maximum emission intensity was obtained at $0.8 \%$ doping of $\mathrm{Cu}$ in $\mathrm{ZnS}$. The reason behind the variation in peak can be explained by the luminescence mechanism of $\mathrm{ZnS}: \mathrm{Cu}$. The doped $\mathrm{Cu}$ ions form deep energy levels between valence band (VB) and $\mathrm{CB}$ of $\mathrm{ZnS}$. As the electrons absorb external energy, they are excited from $\mathrm{VB}$ to $\mathrm{CB}$ and go to the defect levels formed by $\mathrm{Cu}$ ions. Thus, the electrons will recombine with holes in the VB and the holes in the $\mathrm{Cu}$ energy levels from shallow sulfur vacancies by radiative transitions. So the emission is possible from both $\mathrm{ZnS}$ (defect states/sulfur vacancies) and $\mathrm{Cu}$ at the same time having relative contributions variable with different doping concentrations. The energy levels of $\mathrm{Cu}$ ions vary with doping concentration. Thus, slightly different emission wavelengths can be obtained by varying the concentration of $\mathrm{Cu}$ ions. 
From the luminescence mechanism, it is clear that $\mathrm{Cu}$ acts as optically active luminescence centers in ZnS NPs because they substitute $\mathrm{Zn}$ in the lattice and the luminescence from $\mathrm{ZnS}: \mathrm{Cu}$ depends on $\mathrm{Cu}$ concentration. Similar variation in emission spectra has been reported earlier with variation in $\mathrm{Cu}$ doping in host $\mathrm{ZnS} .^{30,31}$ Figure 4(f) shows the optimized luminescence output of $\mathrm{Cu}$ doped core and core-shell QDs. It is clear that optimum doping concentration is $0.8 \%$ (at.) and this was used for synthesis of core-shell QDs. The enhancement in the overall emission for $\mathrm{ZnS}: \mathrm{Cu} / \mathrm{ZnS}$ core-shell QD in comparison to the core was observed. This improvement is due to the passivation of surface defects at the shell which have more probability for non-radiative decay. Figure 4(e) shows broad emission peaks centered at $530 \mathrm{~nm}$ spanning blue green region. Absolute QYs of $\mathrm{Mn}$ doped and $\mathrm{Cu}$ doped QDs were measured using an integrating sphere and a Xenon lamp as excitation source. Mn doped core and coreshell QDs have shown absolute QY from $8.0 \%$ to $14.1 \%$ and $\mathrm{Cu}$ doped core and core-shell QDs have shown absolute QY of $1.8 \%-4.8 \%$, respectively.

Figure 5(a) shows graphical illustration of spectrum that can be generated using phosphor QDs, the inset (right) shows spectrum generated by Compact Florescent Lamp (CFL). It is clear that the emission in visible spectrum generated by CFL bulb does not span the region entirely, resulting in poor photometric properties. The inset (left in figure) shows exemplary spectrum of existing LEDs with green window problem. ${ }^{10}$ Therefore, there are two objectives to be fulfilled, one to get better output in the region of visible spectrum and at the same time achieving high CRI ( $>85)$ from QD phosphors. This can be achieved in two ways: First way is by synthesizing core-shell (or multi core-shell) system to generate white light. In such systems white light is obtained by combining emission from core and shell structure (Figure 5(b)). Second way is to synthesize a mixture of obtained independently radiating QDs (Figure 5(c)).

Assuming the mixture of QDs to be independent radiator, then the resultant emission from both QDs is just a superposition of individual QDs. The generalized formula for emission can be written as

$$
\mathrm{I}_{\mathrm{R}}=\mathrm{I}_{\mathrm{QD}(1)}+\mathrm{I}_{\mathrm{QD}(2)} \cdot
$$

Figure 5(d) shows the resultant output, according to Eq. (2). The emission from individual QDs lies in visible region, while the excitation of both QDs lies in UV $(300 \mathrm{~nm})$ region.
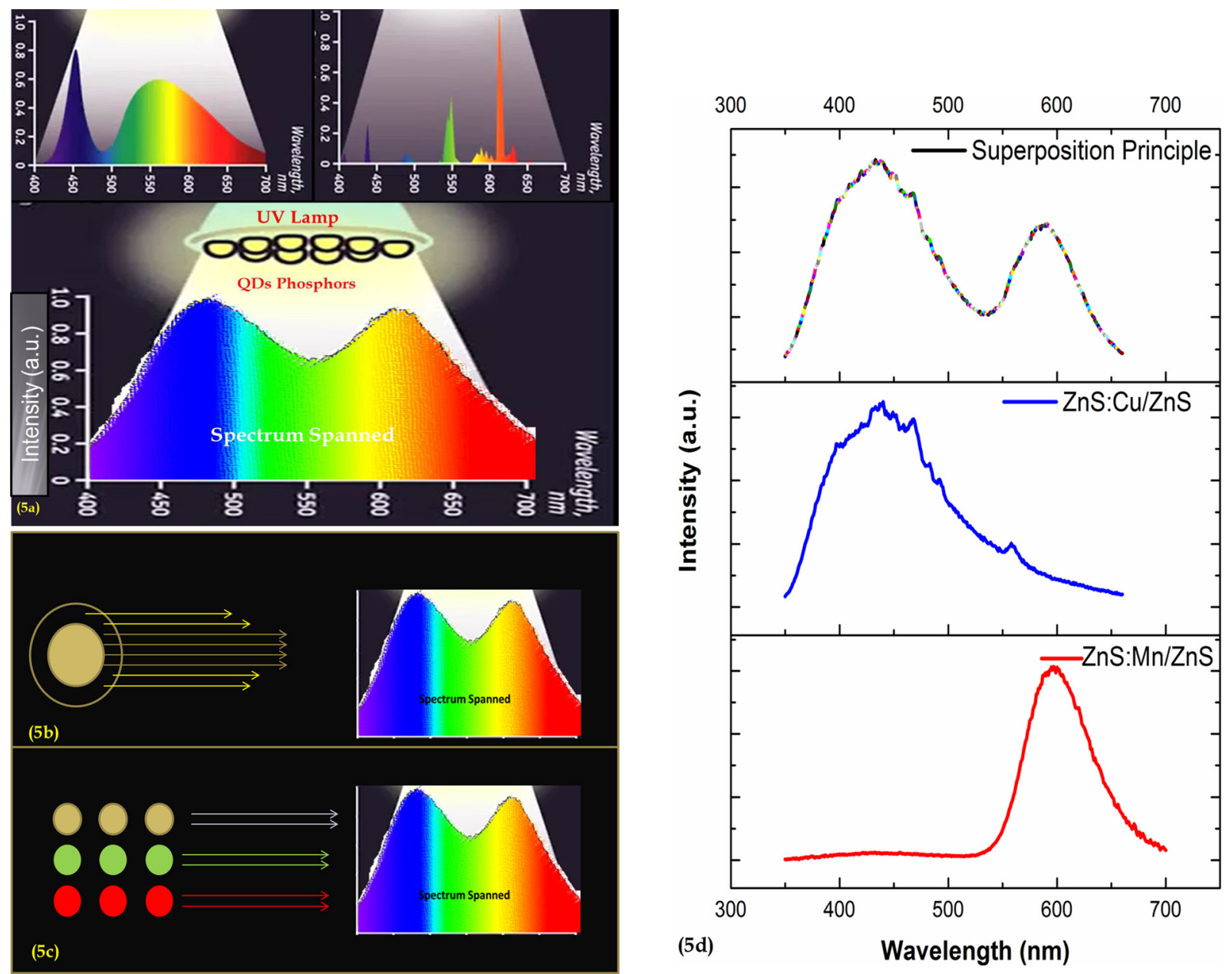

FIG. 5. (a) Emission spectrum generated by mixture of QDs. Inset (right) shows spectrum generated by CFL bulb. Inset (left) shows spectrum of available LEDs, with green window problem, (b) illustrates generation of white light by combining emission from core and shell, (c) illustrates generation of white light by combining emission from independently radiating mixture of quantum dots, (d) theoretically predicted graph according to principle of superposition of solid-solid mixture of $\mathrm{Cu}$ doped and Mn doped core shell NPs. 


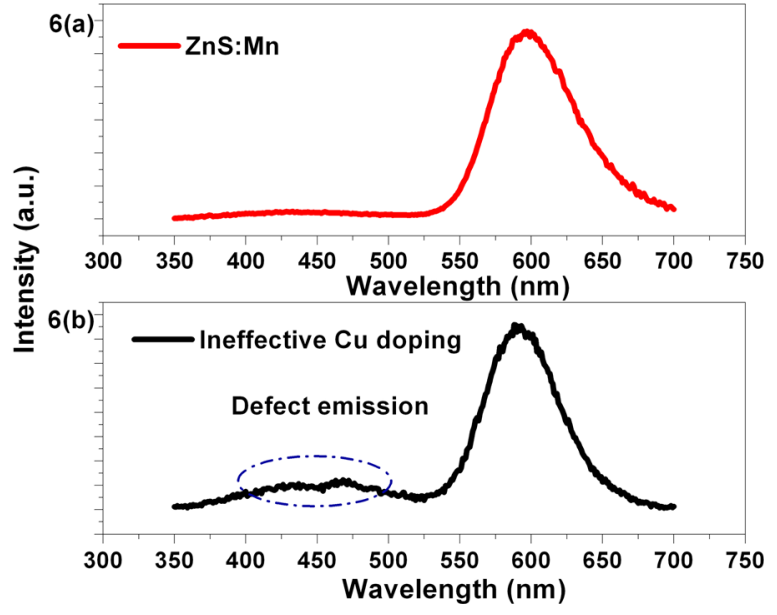

FIG. 6. PL spectrum of (a) ZnS: Mn core and (b) dual doped ZnS:Mn/ ZnS:Cu QDs.

Therefore, it is impossible that emission from one type of QD to be absorbed by the other type, leading to minimize the problem of self-absorption.

To span the whole visible spectrum having good CRI, dual doped materials with $\mathrm{Mn}$ in the core and $\mathrm{Cu}$ in the shell (ZnS:Mn/ZnS:Cu) were tested. Since Mn doped core-shell QDs give bright emission in orange region and $\mathrm{Cu}$ doped core-shell QDs emit in blue green region individually. In order to get better CRI index and lower CCT (Correlated Color Temperature), the emission in orange red region must be increased in comparison to rest of the region, as observed from the experiments [Table SI, Ref. 24]. The main reason for Mn doping in the core instead of the shell is that the output around $550-650 \mathrm{~nm}$ gives better CRI index and low CCT temperature. Mn ions related emission is better in the core in comparison with shell as the core is better passivated. Recently, Hazarika et al. ${ }^{32}$ have reported tuning of Mn emission over the entire visible spectral range at an ensemble scale by controlling the strain generated due to an epitaxial growth of a semiconductor shell over a semiconductor core. Figure 6(a) shows core $\mathrm{ZnS}$ :Mn QDs, showing the dopant related strong emission in orange region. However, it was observed that the $\mathrm{Cu}$ doped in the shell does not give the desired emission (Figure 6(b)). The emission of $\mathrm{Cu}$ in blue green region was very less compared with that of $\mathrm{Mn}$ dopant. The percentage ratio of dopant emission of $\mathrm{Mn}$ vs $\mathrm{Cu}$ comes out to $64.43 \%$. This is because the $\mathrm{Cu}$ dopant is in the shell, which may have defect states (higher in comparison with the
Mn doped core) that are not passivated, thereby increasing the non radiative path ways for blue green emission. Thus, there will be always a problem with the dopant ions exposed to the environment. ${ }^{33,34}$ The multishell structures have been reported earlier, where these materials have large lattice mismatch and are thus difficult to synthesize by simple approaches. In addition, such structures with high photometric properties have not been reported yet.

Following second approach, solid-solid mixture of $\mathrm{Mn}$ and $\mathrm{Cu}$ doped core-shell QDs was formed and the system was again exited at $300 \mathrm{~nm}$ wavelength (Table SI, Ref. 24). The resultant emission is shown in Figure 7. The recorded emission is similar to one theoretically predicted in Figure 5. The PL spectrum of mixture of $\mathrm{Cu}$ doped core-shell QDs and Mn doped core-shell QDs spanning whole spectrum is shown in Figure 7. It is clear that the emission spectrum peaks can be controlled by changing the concentration ratio of $\mathrm{Mn}$ and $\mathrm{Cu}$ doped QDs. The reabsorption of emitted light is a serious loss mechanism in practical situations. Mn based phosphors that also exhibit high stability and quantum efficiency do not suffer from this problem but in turn lack emission tunability, seriously affecting their practical utility. Hazarika et $a l^{32}$ addressed this problem by using strain to tune the dopant related emission. We presented a simple way to tune the output spectrum using non-toxic QDs emitting in different parts of visible spectrum at similar excitation. In Figure 7(a), the emission peaks are proportional to each other, while in Figure 7(b) as we increase the concentration of Mn doped core-shell QDs (samples S3 and S4, Table SI, Ref. 24); the peak around red emission is enhanced corresponding to increased concentration of $\mathrm{ZnS}: \mathrm{Mn} / \mathrm{ZnS}$ core-shell QDs. The effect of different concentrations of $\mathrm{Cu}$ and $\mathrm{Mn}$ doped coreshell QDs on the PL spectrum was studied for all the samples and excitation and emission spectrum of mixture was recorded. The results are summarized in Figure S3 (Ref. 24).

\section{Photometric properties}

Since QDs are promising color conversion phosphors for lighting and opto-electronic applications, they must have high CRI values with CIE close to white light $(0.33,0.33)$. Further to generate the warm and stable white color with QDs, the whole visible spectrum must be spanned. The photometric properties (CIE, CCT, and CRI) of 17 samples with various ratios of $\mathrm{Cu}$ and $\mathrm{Mn}$ doped core shell QDs were studied and their results are depicted in Tables SI and SII (Ref. 24).
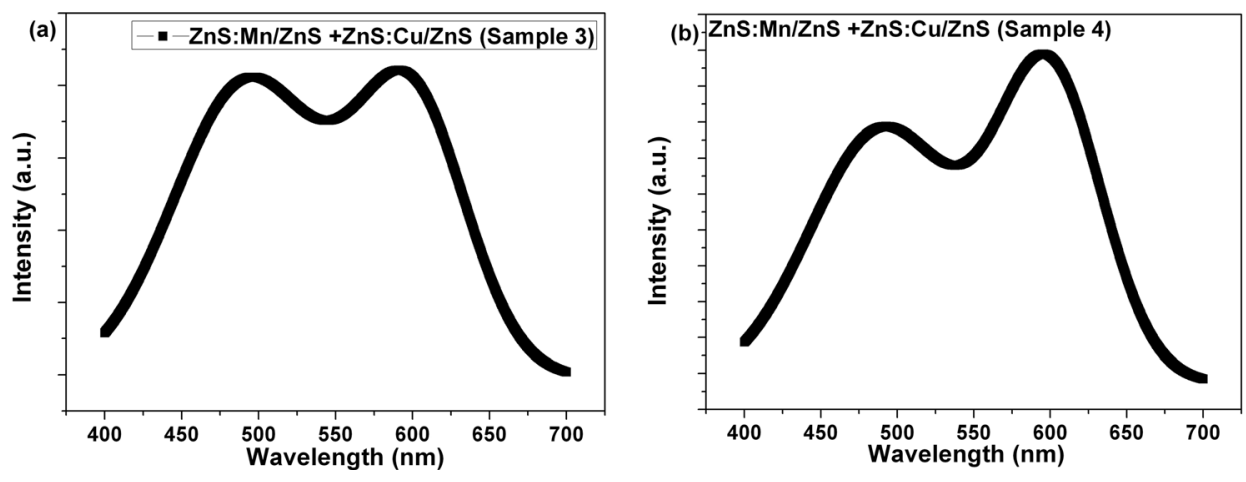

FIG. 7. (a) The PL spectrum of mixture of $\mathrm{ZnS}: \mathrm{Cu} / \mathrm{ZnS}$ and $\mathrm{ZnS}: \mathrm{Mn} / \mathrm{ZnS}$ QD samples spanning the whole spectrum, (b) the peak in red region of spectrum is enhanced as the concentration of $\mathrm{Mn}$ is increased (sample S4). 
TABLE I. Photometric properties of all types of QDs.

\begin{tabular}{lcccc}
\hline \hline S. no. & QD type & \multicolumn{2}{l}{ CIE (X,Y) } & CCT (in K) CRI \\
\hline 1 & ZnS:Mn & $0.49,0.45$ & 2515 & 19 \\
2 & ZnS:Mn/ZnS & $0.48,0.43$ & 2599 & 21 \\
3 & $\mathrm{ZnS}: \mathrm{Cu}$ & $0.32,0.43$ & 611 & 65 \\
4 & $\mathrm{ZnS}: \mathrm{Cu} / \mathrm{ZnS}$ & $0.31,0.41$ & 6109 & 73 \\
5 & $\mathrm{ZnS}: \mathrm{Mn} / \mathrm{ZnS}+\mathrm{ZnS}: \mathrm{Cu} / \mathrm{ZnS}$ (sample S3) & $0.33,0.36$ & 5290 & 88 \\
6 & $\mathrm{ZnS}: \mathrm{Mn} / \mathrm{ZnS}+\mathrm{ZnS}: \mathrm{Cu} / \mathrm{ZnS}$ (sample S4) & $0.35,0.36$ & 4704 & 88 \\
7 & $\mathrm{ZnS}: \mathrm{Mn} / \mathrm{ZnS}: \mathrm{Cu}$ & $0.48,0.39$ & 2217 & 38 \\
\hline \hline
\end{tabular}

On the other hand, Table I summarizes all photometric properties (CIE, CCT, and CRI) of the different types of core-shell QDs. It is clear from Table I that the CRI values increases significantly from $38 \%$ to $88 \%$ for dual doped sample and mixture of different doped samples (samples S3 and S4), respectively. This increase in CRI happens when the whole spectrum was covered by the emission from the QDs (ZnS:Mn/ZnS + ZnS:Cu/ZnS, sample S4) shown in
Figure 7(b). Only ZnS: Mn QDs have low CRI, which increases as a shell is formed, with a slight shift in CIE coordinates $(\Delta x=0.01, \Delta y=0.02)$ as the size of nanoparticle changes after formation of shell, thereby changing the emission. Further, it is seen that CRI value of $38 \%$ for dual doped system ( $\mathrm{ZnS}: \mathrm{Mn} / \mathrm{ZnS}: \mathrm{Cu}$ QDs) is poor because of low emission in $350-550 \mathrm{~nm}$ region compared with $550-700 \mathrm{~nm}$ region. Thus, the resultant white light is not of very good quality that is needed for solid-state lighting devices. However, when solid-solid mixing of samples was done, the emission of both QDs together spans whole of the visible spectrum, resulting in high value of CRI $\sim 88$ (Table SII, Ref. 24). Different samples with various ratios of $\mathrm{Cu}$ doped and Mn doped QDs were formed as depicted in Table SI. It is found that as the Mn doped ratio of QDs was increased the emission in orange red region of spectrum was enhanced compared with that in blue region (Figure S3, Ref. 24). Further the photometric properties of different samples are depicted in Table I and Table SII. With increase in concentration of $\mathrm{Mn}$ doped QDs emission in red region is
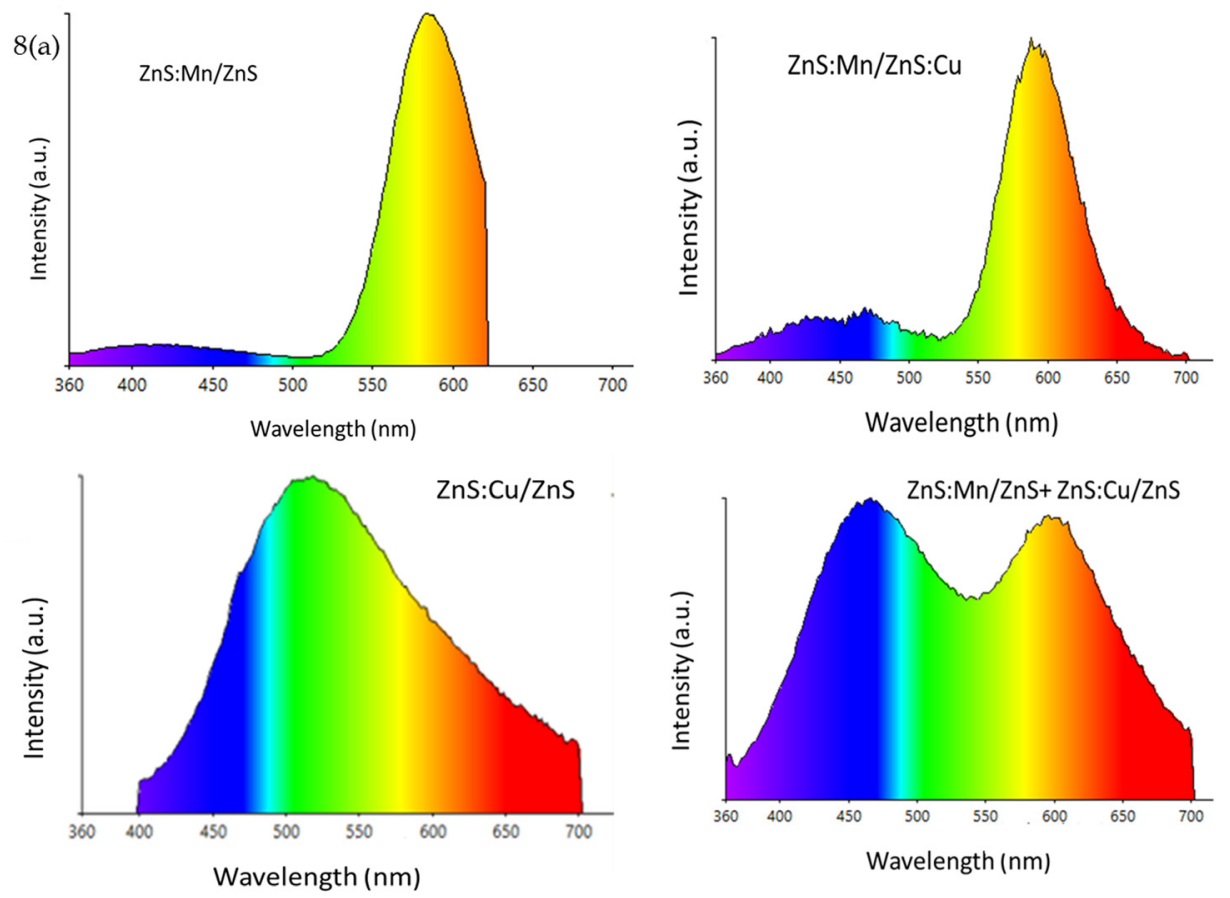

FIG. 8. (a) Emission spectrum spanned by different samples prepared, (b) CIE $(\mathrm{x}, \mathrm{y})$ chromaticity diagram of all the nano luminophores prepared.

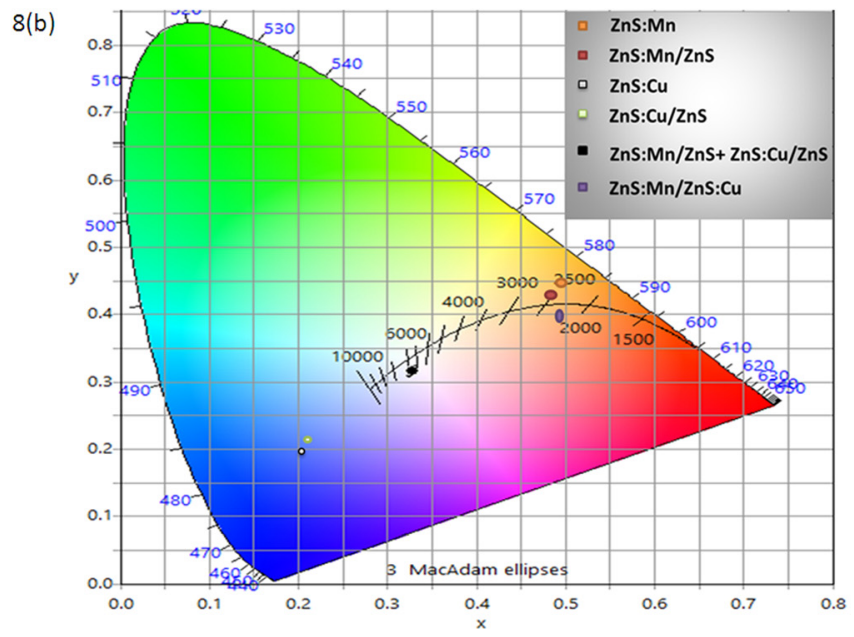


increased (samples 3 and 4) and the CCT becomes less in comparison to other samples as shown in Table SII. In addition, there is a shift in CIE co-ordinates as well from (0.52, $0.40)$ to $(0.33,0.36)$ with an increase in relative concentration of Mn doped QDs with respect to $\mathrm{Cu}$ doped QDs. At the same time, if emission in blue region in comparison with red region decreases, the CRI and color (white) quality also decreases. So there is always a tradeoff between CCT and CIE co-ordinates and balance between both of them by adjusting the synthesis and architecture of the system must be achieved. It was observed that the excitation of both the samples was same, but they emit in different region, so it was possible for combining emissions to span the whole visible spectrum. Figure 8(a) shows the spectrum spanned by different samples. It is clear from the figure that sample S3 spans whole visible spectrum. Figure 8(b) depicts CIE $(\mathrm{x}, \mathrm{y})$ chromaticity diagram of all inorganic nano fluorophores combinations. The dark line represents black body line at different temperature. It is clear from the diagram that the mixture of $\mathrm{Mn}$ and $\mathrm{Cu}$ doped QDs can generate warm white light with CIE $(0.35,0.36)$, CRI 88 , and CCT $4704 \mathrm{~K}$, which indicates that they can be used to develop QD based white LEDs.

\section{CONCLUSION}

In conclusion, we present non cadmium based QD system which can act as a building block for a complete luminescent system needed for potential lighting applications. Different solid-solid mixture of highly luminescent QDs emitting in blue-green and orange region separately were designed to emit white light of good quality under single excitation. The reabsorption problem of mixture (different sized QDs) was successfully addressed since both systems have same excitation and emits differently across the visible spectrum. The resultant mixture have achieved high CRI, however the CCT is a little high in comparison with perfect white light. The CCT of resultant system can be lowered if the emission in the red part of spectrum is further enhanced compared with that of blue green region. The white light emitting system of mixed QDs may lead to a simple device incorporation and improve the overall performance of future solid-state lighting devices. In addition, these doped QDs are safe compared with any of the highly toxic class-A elements $(\mathrm{Cd}, \mathrm{Hg}$, and $\mathrm{Pb})$ and may replace the current intrinsic quantum dot emitters used in display and lighting devices.

\section{ACKNOWLEDGMENTS}

The authors want to thank Dr. Savas Delikanli and Dr. Murat Olutas from UNAM, Bilkent University, Ankara,
Turkey for giving useful suggestions for the improvement of this manuscript.

${ }^{1}$ M. M. Duvenhage, O. M. Ntwaeaborwa, H. C. Swart, and M. J. H. Hoffman, NSTI- Nanotech. 1, 543 (2010).

${ }^{2}$ M. Chattopadhyay, P. Kumbhakar, C. S. Tiwary, R. Sarkar, A. K. Mitra, and U. Chatterjee, J. Appl. Phys. 105, 024313 (2009).

${ }^{3}$ Q. Xiao and C. Xiao, Appl. Surf. Sci. 254, 6432 (2008).

${ }^{4}$ R. Sarkar, C. S. Tiwari, P. Kumbhakar, S. Basu, and A. K. Mitra, Physica E 40, 3115 (2008).

${ }^{5}$ R. Kripal, A. K. Gupta, S. K. Mishra, R. K. Srivastava, A. C. Pandey, and S. G. Prakash, Spectrochim. Acta, Part A 76, 523 (2010).

${ }^{6}$ T. T. Q. Hoa, N. D. The, S. McVitie, N. H. Nam, L. V. Vu, T. D. Canh, and N. N. Long, Opt. Mater. 33, 308 (2011).

${ }^{7}$ B. Dong, L. Cao, G. Sua, and W. Liu, J. Colloid Interface Sci. 367, 178 (2012).

${ }^{8}$ L. Cao, J. Zhang, S. Ren, and S. Huang, Appl. Phys. Lett. 80, 4300 (2002).

${ }^{9}$ T. Kubo, T. Isobe, and M. Senna, J. Lumin. 99, 39 (2002).

${ }^{10}$ A. Kitai, Luminescent Materials and Applications (John Wiley \& Sons, 2008).

${ }^{11}$ S. Jana, B. B. Srivastava, and N. Pradhan, J. Phys. Chem. Lett. 2, 1747 (2011).

${ }^{12}$ A. K. Kole, C. S. Tiwary, and P. Kumbhakar, J. Appl. Phys. 113, 114308 (2013).

${ }^{13}$ S. Murano, M. Burghart, J. Birnstock et al., Proc. SPIE 5937, 79 (2005).

${ }^{14}$ S. C. Erwin, L. Zu, M. I. Haftel, A. L. Efros, T. A. Kennedy, and D. J. Norris, Nature 436, 91 (2005).

${ }^{15}$ A. Nag and D. D. Sharma, J. Phys. Chem. C 111, 13641 (2007).

${ }^{16}$ M. J. Bowers II, J. R. McBride, and S. J. Rosenthal, J. Am. Chem. Soc. 127, 15378 (2005).

${ }^{17}$ C. C. Shen and W. L. Tseng, Inorg. Chem. 48, 8689 (2009).

${ }^{18}$ A. A. Bol and A. Meijerink, Phys. Chem. Chem. Phys. 3, 2105 (2001).

${ }^{19}$ K. W. Cheah, L. Ling, and X. Huang, Nanotechnology 13, 238 (2002).

${ }^{20}$ S. K. Panda, S. G. Hickey, H. V. Demir, and A. Eychmuller, Angew. Chem. 123, 4524-4528 (2011).

${ }^{21}$ Z. Quan, D. Yang, C. Li, D. Kong, P. Yang, Z. Cheng, and J. Lin, Langmuir 25, 10259 (2009).

${ }^{22}$ B. W. D. Andrade, M. E. Thompson, and S. R. Forrest, Adv. Mater. 14, 147 (2002).

${ }^{23}$ M. Sharma, T. Jain, S. Singh, and O. P. Pandey, AIP Adv. 2, 012183 (2012).

${ }^{24}$ See supplementary material at http://dx.doi.org/10.1063/1.4927482 for XRD, band gap, luminescence studies, and Tables SI, SII, and SIII.

${ }^{25}$ Powder diffraction File, No. 77-2100 JCPDS International Center for Diffraction Data, 1982.

${ }^{26}$ J. I. Pankove, Optical Processes in Semiconductors (Prentice-Hall, Englewood Cliffs, NJ, 1971).

${ }^{27}$ M. Sharma, S. Singh, and O. P. Pandey, J. Appl. Phys. 107, 104319 (2010).

${ }^{28}$ V. K. Sharma, B. Guzelturk, T. Erdem, Y. Kelestemur, and H. V. Demir, ACS Appl. Mater. Interfaces 6, 3654 (2014).

${ }^{29}$ R. N. Bhargava, J. Lumin.70, 85 (1996).

${ }^{30}$ K. T. Al-Rasoul, N. K. Abbas, and Z. J. Shanan, Int. J. Electrochem. Sci. 8, 5594 (2013).

${ }^{31}$ R. Sreeja, K. Sridharan, R. Philip, and M. K. Jayaraj, Opt. Mater. 36, 861 (2014).

${ }^{32}$ A. Hazarika, A. Pandey, and D. D. Sarma, J. Phys. Chem. Lett. 5, 2208 (2014).

${ }^{33}$ R. B. Little, M. A. EI-Sayed, G. W. Bryant, and S. J. Burke, Chem. Phys. 114, 1813 (2001).

${ }^{34}$ J. J. Li, A. Wang, W. Guo, J. C. Keay, T. D. Mishima, M. B. Johnson, and X. Peng, J. Am. Chem. Soc. 125, 12567 (2003). 